Article

\title{
Polystyrene-Poly(methyl methacrylate) Silver Nanocomposites: Significant Modification of the Thermal and Electrical Properties by Microwave Irradiation
}

\author{
Edreese H. Alsharaeh \\ College of Science and General Studies, Alfaisal University, P.O. Box 50927, Riyadh 11533, Saudi Arabia; \\ ealsharaeh@alfaisal.edu; Tel.: +966-1-215-7739 \\ Academic Editor: Dinesh Agrawal \\ Received: 4 March 2016; Accepted: 3 June 2016; Published: 13 June 2016
}

\begin{abstract}
This work compares the preparation of nanocomposites of polystyrene (PS), poly(methyl methacrylate) (PMMA), and PSMMA co-polymer containing silver nanoparticles (AgNPs) using in situ bulk polymerization with and without microwave irradiation (MWI). The AgNPs prepared were embedded within the polymer matrix. A modification in the thermal stability of the PS/Ag, PMMA/Ag, and PSMMA/Ag nanocomposites using MWI and in situ was observed compared with that of neat PSMMA, PS, and PMMA. In particular, PS/Ag, and PSMMA/Ag nanocomposites used in situ showed better thermal stability than MWI, while PMMA/Ag nanocomposites showed improved thermal stability. The electrical conductivity of the PS/Ag, PMMA/Ag, and PSMMA/Ag composites prepared by MWI revealed a percolation behavior when $20 \%$ AgNPs were used as a filler, and the conductivity of the nanocomposites increased to $103 \mathrm{~S} / \mathrm{cm}, 33 \mathrm{~S} / \mathrm{cm}$, and $40 \mathrm{mS} / \mathrm{cm}$, respectively. This enhancement might be due to the good dispersion of the AgNPs within the polymer matrix, which increased the interfacial interaction between the polymer and AgNPs. The polymer/Ag nanocomposites developed with tunable thermal and electrical properties could be used as conductive materials for electronic device applications.
\end{abstract}

Keywords: nanocomposites; silver nanoparticles; microwave irradiation; polymer; X-ray diffraction

\section{Introduction}

Recently, nano- and thin-film technologies based on novel systems associating metal particles with a polymer matrix have achieved unique physical and mechanical properties that were not possible with the addition of micron-sized particles. These metal nanoparticles (NPs) embedded in host polymer matrices have become the focus of increasing attention because of their applications in many fields including optical fibers, sub-wavelength waveguides, nonlinear optical switches [1], superlenses [2], magnetooptic data storages, directional connectors, electronics as nanowires [3] for biomedical materials, NP barcode labels [4,5], sensitive materials for DNA screening [6], biosensors [7], and bio-films with anti-microbial effects of $\mathrm{Ag}$ [8] materials. $\mathrm{Ag}, \mathrm{Au}$, and $\mathrm{Cu}$ NPs are reported to exhibit a strong biocidal effect on more than 16 species of bacteria including Escherichia coli [9-11]. In addition, these polymers are attractive materials for application in biosensors because of the considerable flexibility in their chemical structures and their redox characteristics [12]. The extent of modification of the property depends on the base polymer; size, distribution, and dispersion of the NPs; and adhesion at the filler-matrix interface [13]. When the NPs are embedded or encapsulated in a polymer, the polymer acts as a surface capping agent. In addition, casting of film becomes easier, and the particle size is controlled well within the desired regime. However, the key problems in this area involve the synthesis and functionalization of the NPs and their dispersion in a polymer matrix. Ag and Au are favorite NP-coating materials because of their well-known property of exhibiting optical absorption 
(plasmons) in the visible region. Ag has been widely studied because it is more reactive than Au. Polymers are usually flexible, lightweight, and able to provide required immobilization of the NPs, avoiding their coalescence or segregation, thus protecting the novel size-dependent properties of the nanomaterials. However, depending on the polymer as well as the concentration of the NPs, the properties of nanocomposites may change. Among various polymers, poly(methyl methacrylate) (PMMA) is a highly transparent plastic with good mechanical strength and is used variously for optical and medical applications [14,15]. In addition, polystyrene (PS) exhibits many admirable properties such as biocompatibility, nontoxicity, high surface area, strong adsorption ability, and chemical inertness [16-18]. Additionally, the co-polymer of methyl methacrylate and styrene (PSMMA) is an important polymeric material that has numerous applications in medicine (e.g., as bone cement); dentistry (e.g., dentures); and the paper, paint, and automotive industries $[19,20]$. There have been many reports on AgNPs in polymers using different techniques [21,22] including solution mixing, melt blending, in situ polymerization, and in situ polymerization using microwave irradiation (MWI) $[23,24]$. However, it is extremely difficult to homogenously disperse NPs into the polymer matrix because of the easy agglomeration of the NPs and the high viscosity of the polymer. The MWI method offers a fast and easy way to synthesize polymer/AgNPs materials. In MWI, dielectric heating energy is transferred directly to the reactants. Energy is supplied to the molecules faster than they are able to relax, which creates high instantaneous temperatures and increases the yield and quality of the products [25-28].

Percolation concepts are used to describe an abrupt transition from one behavior to another caused by the formation of long-range networks and have been used to describe the concentration-dependent insulator-to-conductor transition in composites of conductive fillers in insulating matrices, particularly polymer nanocomposites. These composites are technologically useful because they combine the easy processability of the polymer matrix with the desirable electrical conductivity of the filler network. Such nanocomposites could find applications in static-discharge housing and packaging for electronics; electromagnetic interference shielding; and lightweight, flexible conductors for electrodes, circuits, displays, and sensors [29].

There have been numerous reports on the usage of AgNPs as conducting-filler-based polymer composites, where improved thermal, mechanical, and electrical properties of the composites were achieved [30-32]. White et al. [32] reported the electrical percolation behavior in Ag nanowire-PS composites. These researchers showed that the conductivity of the composites can be easily tuned by modifying the aspect ratio of nanowires, and Ag nanowires are superior to carbon nanotubes because they are straight, sufficiently large that minimal interparticle variation in electrical conductivity is achieved, and disperse easily into experimental solvents and polymers. In another report, Lee et al. [31] prepared PMMA/polyaniline (PANI) / Ag composites using an electroless coating of Ag on a PMMA sphere pre-coated with PANI using in situ chemical polymerization. These researchers reported that the resistivity of the PMMA/Ag and PMMA/PANI/Ag composites varied between $10^{14}$ and $10^{-1} \Omega \cdot \mathrm{cm}$ and $10^{8}$ and $10^{-4} \Omega \cdot \mathrm{cm}$, respectively.

Despite the numerous reports on composites of PS with PMMA or AgNPs, very few studies have been performed on the combination of these three components. However, the development of polymer-AgNPs nanocomposites that can fully utilize conducting filler properties and achieve significantly enhanced electrical and thermal properties with low AgNPs loading remains necessary.

In this paper, PSMMA/AgNPs nanocomposites were synthesized with a low concentration (20\%) loading of AgNPs via in situ bulk polymerization using MWI. To the best of our knowledge, this report is the first on the enhancement of the thermal and electrical properties of PSMMA/Ag nanocomposites with percolation behavior using only $20 \%$ AgNPs filler, which exhibits a higher conductivity. Combining the advantages of PS, PMMA, and AgNPs, the nanocomposites exhibited many excellent properties, such as good solubility and dispersibility in water, satisfactory biocompatibility, and high electrical conductivity. The synthesized nanocomposites were characterized using Fourier-transform infrared spectroscopy (FTIR), ultraviolet/visible (UV/Vis) spectroscopy, X-ray photoelectron spectroscopy (XPS), Raman spectroscopy, X-ray diffraction (XRD), scanning electron 
microscopy (SEM), high-resolution transmission electron microscopy (HRTEM), differential scanning calorimetry (DSC), thermal gravimetric analysis (TGA), and electrical conductivity measurements to provide an understanding of the structure-property relationships as well as the percolation threshold behavior.

\section{Results and Discussion}

The size and structure of the AgNPs in the polymer matrix were investigated using XRD studies; therefore, XRD patterns of the polymer/Ag nanocomposites were also obtained. Figure 1 presents XRD patterns of the AgNPs and polymer/Ag nanocomposites. As observed in Figure 1a, the pure AgNPs exhibit a crystalline nature with FCC structure with peaks corresponding to (111), (200), (220), and (311) planes. These results are consistent with the previous literature values for AgNPs and JCPDS No. 00-003-0921. Figure 1b-d presents XRD patterns of the polymer/AgNPs composites, which exhibit a two-phase (crystalline and amorphous) structure. The polymer/AgNPs exhibit the broad reflection and typical amorphous nature for the polymer, as expected, and the typical pattern of the face FCC Ag crystalline structure indicates the formation of metallic Ag.

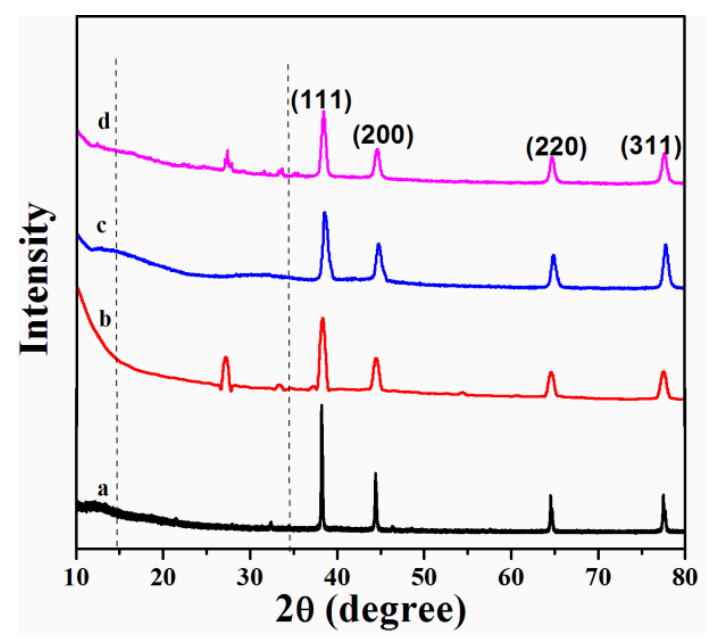

Figure 1. XRD patterns of (a) AgNPs and (b) PS/AgNPs; (c) PMMA/AgNPs; and (d) PSMMA/AgNPs nanocomposites.

Furthermore, the width of the (111) peak was employed to calculate the average crystallite size using the Scherrer equation [33]:

$$
D=0.9 \lambda /(B \times \cos \theta)
$$

where $\lambda$ is the wavelength of the incident $\mathrm{Cu} \mathrm{K} \alpha \mathrm{X}$-ray $(1.514 \AA)$, B is the full width at half maxima (FWHM) of the diffraction peak, and $\theta$ is the diffraction angle. The calculated average sizes for the AgNPs and polymer/AgNPs were observed to be $46 \mathrm{~nm}$ and 18, 16, and $13 \mathrm{~nm}$ for PS/AgNPs, PMMA/AgNPs, and PSMMA/AgNPs, respectively. The particle size was observed to be smaller for the PSMMA/AgNPs nanocomposites than for the AgNPs. However, for the different polymer composites, the particle size did not vary greatly. The decrease in intensity and broadening of peaks in the AgNPs/polymers (Figure 1b-d) reflects the decrease in particle size of the polymer/AgNPs compared with that of the AgNPs (Figure 1a). The particle size calculated by XRD was further confirmed by TEM analysis.

To confirm the chemical structure of all the polymer/Ag composites, FTIR spectral analysis was performed. Figure 2 presents FTIR spectra of the PS/Ag, PMMA/Ag, and PSMMA/Ag nanocomposites. For the PS/Ag nanocomposites, the spectrum shows the presence of the characteristic bands of PS at 3060, 2920, and $2840 \mathrm{~cm}^{-1}$, which correspond to the aromatic ring and aliphatic C-H and $-\mathrm{CH}_{2}$ stretching, respectively. The aromatic overtones are observed at $1680-2000 \mathrm{~cm}^{-1}$, and aromatic $\mathrm{C}=\mathrm{C}$ stretching is observed at $1613 \mathrm{~cm}^{-1}$. For the PMMA/AgNPs, the spectrum shows characteristic bands of the aliphatic $\mathrm{C}-\mathrm{H}$ and $-\mathrm{CH}_{2}$ at 2925 and $2852 \mathrm{~cm}^{-1}$, respectively; the bands 
were reduced in intensity and became broader compared with the neat PMMA (Figure S1). The bands at $1270-1000 \mathrm{~cm}^{-1}$ originated from the $\mathrm{C}-\mathrm{H}$ deformations and $\mathrm{C}-\mathrm{O}-\mathrm{C}$ and $\mathrm{C}-\mathrm{O}$ stretching. The band at $1747 \mathrm{~cm}^{-1}$ is assigned to the $\mathrm{C}=\mathrm{O}$ stretching vibrations of the ester group of the PMMA. It was observed that this band shifted more in the nanocomposites than the peak previously reported for neat PMMA at $1730 \mathrm{~cm}^{-1}$ [24]. For the PSMMA/Ag nanocomposites, the FTIR spectrum shows the typical characteristic bands at 2930 and 2860 and 1600 and $1460 \mathrm{~cm}^{-1}$ which correspond to the aliphatic C-H and $-\mathrm{CH}_{2}$ and aromatic $\mathrm{C}=\mathrm{C}$ stretching, respectively, in the PS molecules. In contrast, characteristic bands at 1745 and $1160-1120 \mathrm{~cm}^{-1}$, which correspond to $\mathrm{C}=\mathrm{O}$ stretching vibrations of ester carbonyl and $\mathrm{C}-\mathrm{O}-\mathrm{C}$ stretching vibrations, respectively, appear for the PMMA molecules [17]. Notably, the FTIR results of the polymer/Ag nanocomposites (Figure 2) demonstrate that some characteristic peaks in the aromatic of PS and ester of PMMA regions are shifted to much higher wave numbers compared with neat polymers (Figure S1). This finding may suggest that this shift is due to $\pi-\pi$ stacking and acrylate interactions, which may be attributed to the contribution toward the stabilization of the AgNPs metal surface. These FTIR results may suggest that the $\pi-\pi$ bonds of PS and acrylate of PMMA were opened by the MWI, which will induce more electron chain transfer sites and will thus promote more interactions between polymers and $\mathrm{Ag}$.

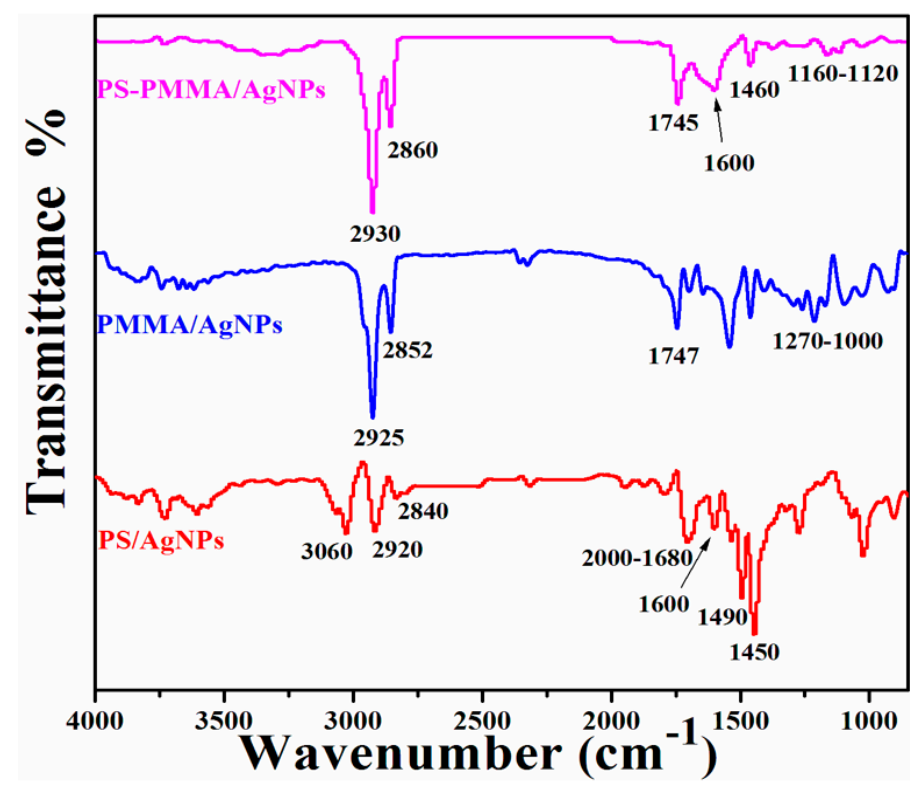

Figure 2. FTIR spectra of polymer/AgNPs nanocomposites.

Further study on the formation of AgNPs on the surface of nanocomposites was performed using XPS, and the results are presented in Figure 3. XPS is a powerful and reliable technique for exploring the interaction of Ag NPs and polymers. The XPS survey spectra of the polymer/AgNPs (not shown here) indicated that not only $\mathrm{Ag}, \mathrm{O}$, and $\mathrm{C}$ were present. Detailed scans of $\mathrm{Ag} 3 \mathrm{~d}, \mathrm{C} 1 \mathrm{~s}$, and $\mathrm{O} 1 \mathrm{~s}$ are presented in Figure $3 a-c$, respectively. In Figure 3a, the peak observed in the energy region of the $\mathrm{Ag} 3 \mathrm{~d}$ transition is symmetrical, and two characteristic binding energy peaks for $\mathrm{Ag} 3 \mathrm{~d}$ for metallic $\mathrm{Ag}$ at 374.33 and $368.33 \mathrm{eV}$ are observed, corresponding to doublets of $\mathrm{Ag} 3 \mathrm{~d}_{3 / 2}$ and $\mathrm{Ag} 3 \mathrm{~d}_{5 / 2}$ [34], respectively. These results indicate the metallic nature of $\mathrm{Ag}$, and no evidence for the existence of $\mathrm{Ag}^{+}$ was obtained. Therefore, the XPS study confirmed the success of the formation of metallic AgNPs within the PS/Ag, PMMA/Ag, and PSMMA/Ag nanocomposites.

Notably, for the PSMMA/Ag nanocomposites (Figure 3), the extent of two binding energies corresponding to doublet $\mathrm{Ag} 3 \mathrm{~d}_{3 / 2}$ and $\mathrm{Ag} 3 \mathrm{~d}_{5 / 2}$ were shifted to the lower side compared with the characteristic peaks of metallic Ag. This lower side shift $(\sim 0.05 \mathrm{eV})$ is possibly due to the stronger interaction between $\mathrm{Ag}$ and $\mathrm{O}$ in $\mathrm{C}=\mathrm{O}$ groups promoted using MWI by enhancing electron transfer from the electron-rich acrylates of PMMA groups to AgNPs. 


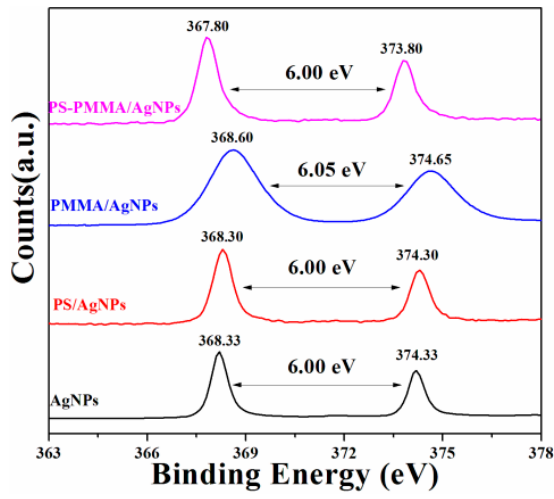

(a)

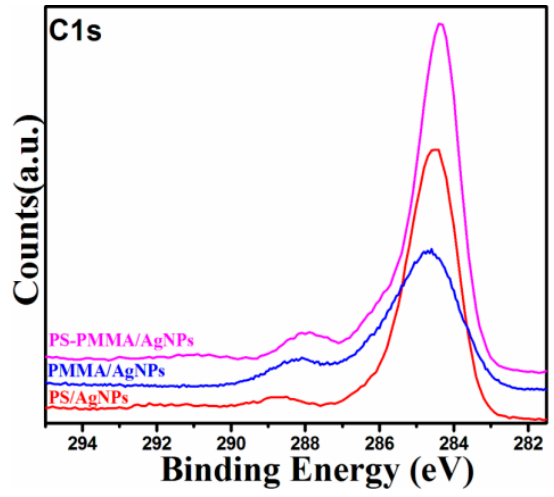

(b)

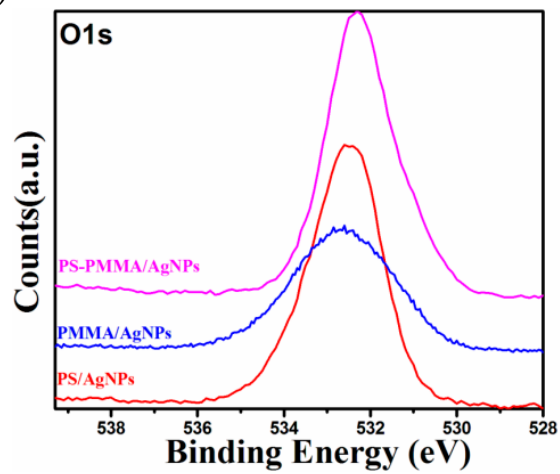

(c)

Figure 3. (a) Ag 3d XPS spectra of AgNPs; (b) C 1s XPS; and (c) O 1s spectra of polymer/AgNPs nanocomposites.

Figure $3 b, c$ presents the $C 1$ s and $O$ 1s spectra of the Ag/polymer system. The peaks are wide and symmetrical. For PS/AgNPs, three different carbon functionalities are considered: (1) hydrocarbon $(\underline{\mathrm{C}}-\mathrm{H} / \mathrm{C}-\mathrm{C})$ at $284.6 \mathrm{eV}$; (2) alcohol or ether $(\underline{\mathrm{C}}-\mathrm{OH} / \mathrm{C}-\mathrm{O}-\mathrm{C})$ at $285.9 \mathrm{eV}$; and $(3)$ ester $(\mathrm{O}-\mathrm{C}=\mathrm{O})$ at $288.6 \mathrm{eV}$ [35,36], mainly due to the presence of the carbon atoms in $\mathrm{C} 12 \mathrm{H} 25 \mathrm{SH}$ introduced onto the AgNPs. For the PMMA/AgNPs and PSMMA/AgNPs, the profile of the C 1 s line was altered, indicating that there was a change in the intensity of its three components, as observed in Figure 3b,c. In addition, the binding energy was observed to shift toward the lower side for all three components of the carbon peaks. This lower side shift in the binding energy occurred because Ag tends to lose unpaired valence electrons; therefore, a strong $A-C$ interaction would result in a shift of the $C 1 \mathrm{~s}$ peak toward low binding energy. This claim was further confirmed by considering the $\mathrm{O} 1 \mathrm{~s}$ spectra (Figure 3c). The O 1s core-level peaks of the polymer/AgNPs are presented in Figure 3c. As resolved by deconvolution, the $\mathrm{O} 1 \mathrm{~s}$ spectrum consisted of a $\mathrm{BE}$ peak at $532.6 \mathrm{eV}$ related to the $\mathrm{O}-\mathrm{C}=\mathrm{O}$ group $[37,38]$. This result implies interaction between $\mathrm{Ag}$ and $\mathrm{O}$, especially between $\mathrm{Ag}$ and $\mathrm{O}-\mathrm{C}=\mathrm{O}$ groups. A shift in the binding energy to the lower side was observed for the PMMA/AgNPs and PSMMA/AgNPs nanocomposites, and the electron transfer from the Ag to the oxygen led to a shifting in the $\mathrm{O} 1 \mathrm{~s}$ binding energy. The reaction between $\mathrm{Ag}$ and $\mathrm{O}$ and even polymers should be responsible for the variation.

The formation of AgNPs in the polymer matrix was also confirmed by UV-Vis spectra of the PS/Ag, PMMA/Ag, and PSMMA/Ag nanocomposites (Figure 4). The weak absorption band of the AgNPs at approximately $410-420 \mathrm{~nm}$ corresponds to the characteristic peak of metallic silver [39-41]. The spectra clearly demonstrate that the absorption peaks of PSMMA/AgNPs nanocomposites were red-shifted to higher wavelength compared with the PMMA/AgNPs and PS/AgNPs nanocomposites, respectively. This finding indicates the restoration of the electronic conjugation within the polymer matrix and the formation of AgNPs [31]. A very weak peak characterized the absorption peak of the 
AgNPs dispersion into the polymer matrix, which might be attributed to a non-aggregated dispersion of NPs [42].

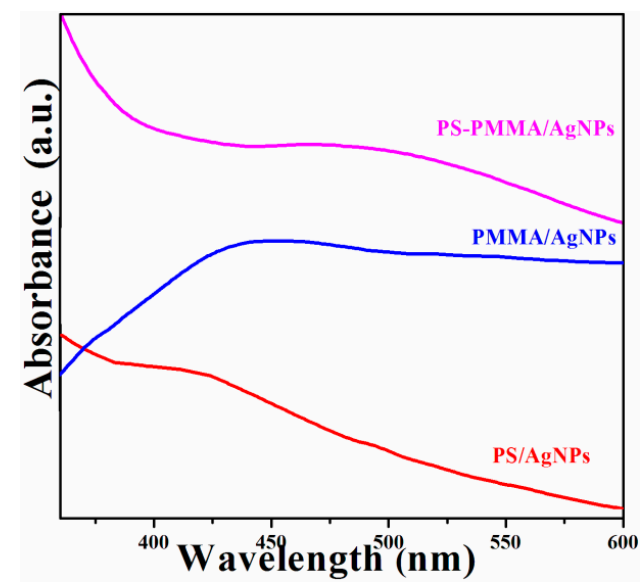

Figure 4. UV spectra of polymer/AgNPs nanocomposites.

The compositions of the polymer/AgNPs nanocomposites were further examined using Raman spectroscopy (Figure 5). Raman spectroscopy is a powerful tool that provides essential information for evaluating the covalent modification of composites. The Raman spectra of the neat polymers (Figure S2) reveal the major scattering peaks of PS and PMMA. The PS spectrum contains peaks at 1602 and $1585 \mathrm{~cm}^{-1}$ due to stretching of benzene rings. The PMMA spectrum (Figure S2) shows characteristic peaks at 600 and $812 \mathrm{~cm}^{-1}$ due to stretching of $\mathrm{C}-\mathrm{C}-\mathrm{O}$ and $\mathrm{C}-\mathrm{COO}$ as well as $\mathrm{C}-\mathrm{O}-\mathrm{C}$, respectively, at $1450 \mathrm{~cm}^{-1}$ due to in-plane bending of $\mathrm{C}-\mathrm{H}$ and at $1728 \mathrm{~cm}^{-1}$ due to stretching of $\mathrm{C}=\mathrm{O}$ [43]. The most prominent peak appearing at $2951 \mathrm{~cm}^{-1}$ is due to the $\mathrm{C}-\mathrm{H}$ stretching vibration. Notably, the locations of the characteristics peaks of all the polymer/Ag nanocomposites (Figure 5) were blue-shifted, which might indicate interfacial interaction between the AgNPs and the polymer matrix.

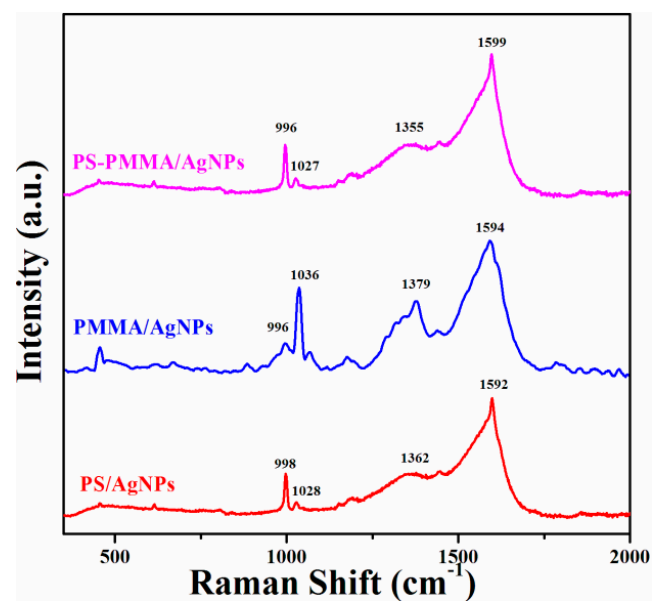

Figure 5. Raman spectra of polymer/AgNPs nanocomposites.

The morphology of the polymer/Ag nanocomposites was studied using SEM and HRTEM, and the results are presented in Figures 6-8. Various reports have shown that the incorporation of NPs into polymer resins can improve the mechanical and rheological properties or even introduce novel functionalities [44-48]. The important factors involved in improving these properties are the type, size, shape, and aspect ratio of the NPs; particle dispersion in polymer resins; and interfacial interaction between organic polymer resins and inorganic NPs. Figure 6a presents an SEM image of AgNPs of polyhedral shape with agglomerated morphology, indicating the high surface energy of these 
particles. The SEM micrograph of PS/AgNPs (Figure 6b) clearly reveals that very small sizes of Ag are dispersed at the surface and embedded within the PS matrix. The SEM micrograph of the PMMA/Ag nanocomposites (Figure 6c) shows that the polyhedral shaped AgNPs are dispersed within the PMMA matrix and are well separated from each other. For the PS-PMMA/Ag nanocomposites (Figure 6d), the AgNPs (white spots) are anchored and dispersed within the PSMMA matrix. According to the MARTINI force field, different values of the strength of interaction of $\varepsilon$ represent levels of hydrophilicity/hydrophobicity [49]. A larger value of $\varepsilon$ provides a more attractive interaction among highly polar groups, whereas a smaller one reflects a lower degree of hydrophobic repulsion between polar and nonpolar phases. The size and shape of the NPs can play an important role in changing the properties of nanocomposites. It has been experimentally determined that nanocomposites with smaller-sized NPs exhibit better performance than those containing larger-sized NPs [50-52]. In the present work, the NPs in the PSMMA/AgNPs nanocomposites were smaller compared with those of the other polymer composites, thus increasing the density at the polymer-NP interface. These results clearly suggest that the AgNPs were successfully embedded in the polymer matrix and modified the functional properties of the polymer.
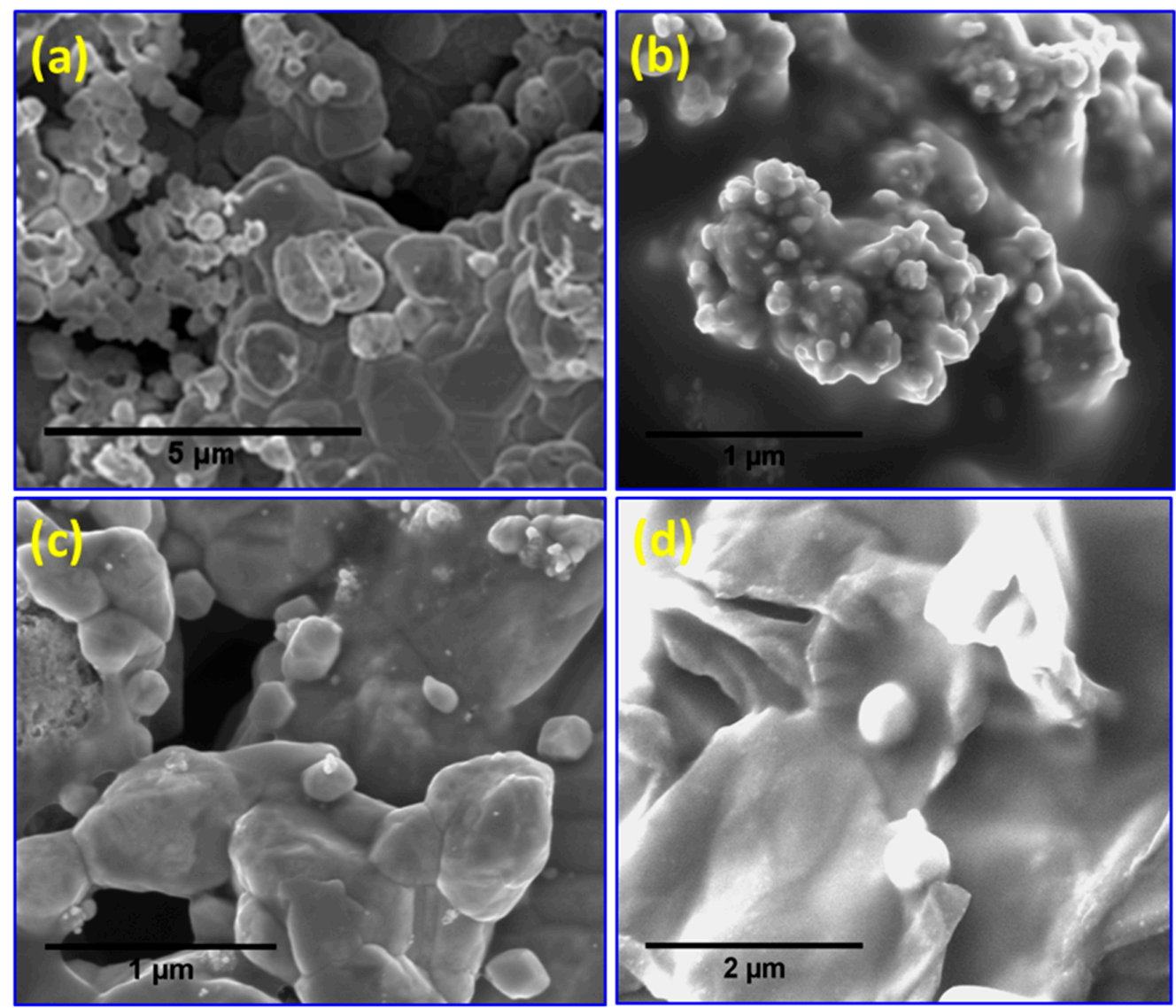

Figure 6. SEM micrographs of (a) AgNPs and (b) PS/AgNPs; (c) PMMA/AgNPs; and (d) PSMMA/AgNPs nanocomposites.

The morphology of the nanocomposites and formation of AgNPs were further studied using HRTEM, and the results are displayed in Figure 7. The HRTEM images of all the polymer/Ag nanocomposites (Figure 7b-d) reveal good dispersion of AgNPs within the polymer matrices, with better homogeneity for PSMMA/Ag (Figure 7d) compared with the other nanocomposites (Figure 8b,c). The good dispersion and poor aggregation resulted from the van der Waals attraction between the particles, indicating the stabilization of AgNPs, which may be due to the electron transfer interaction 
between polymers and AgNPs. This finding is consistent with the XPS results and our previous work [17].
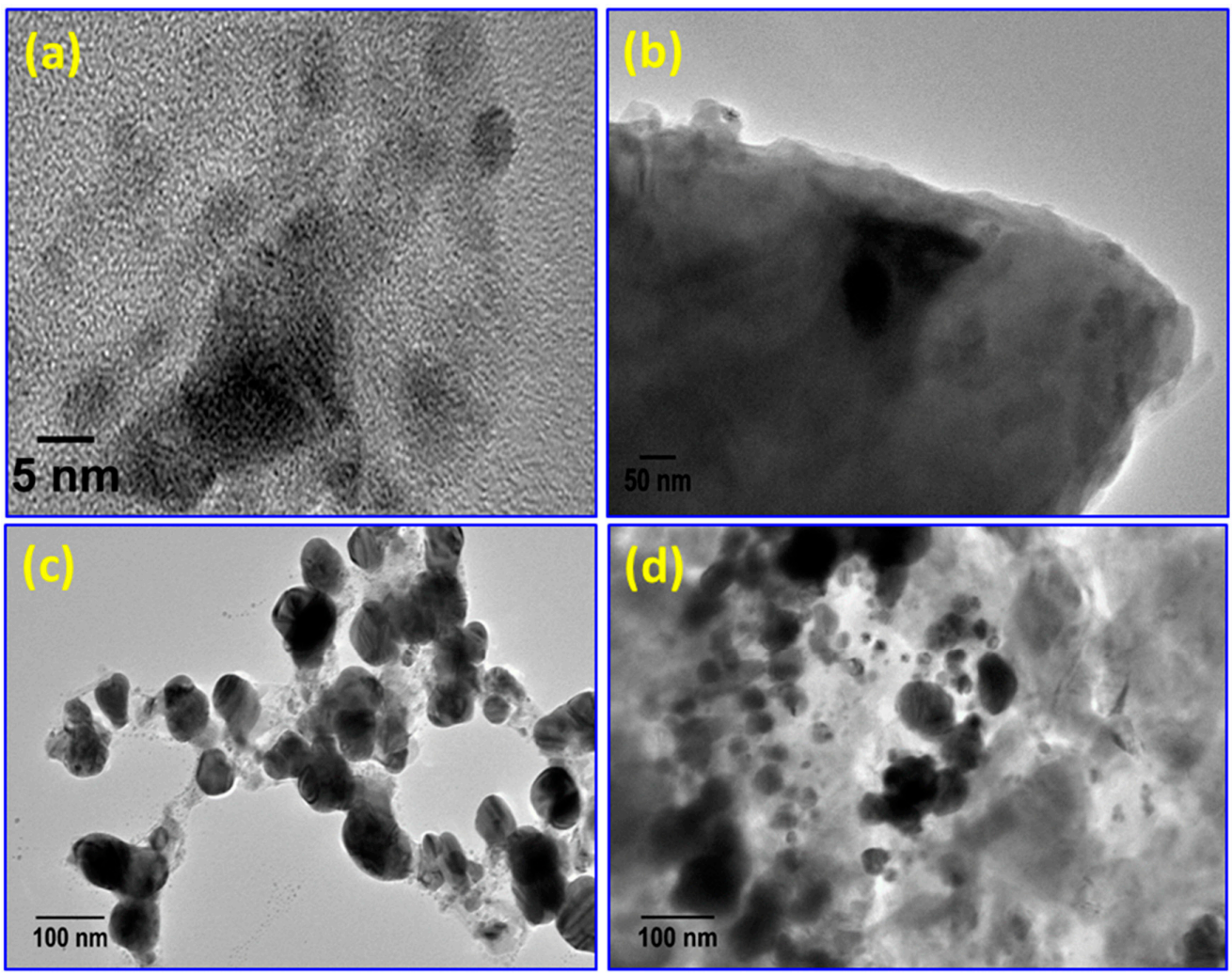

Figure 7. HRTEM micrographs of (a) AgNPs and (b) PS/AgNPs; (c) PMMA/AgNPs; and (d) PSMMA/AgNPs nanocomposites.
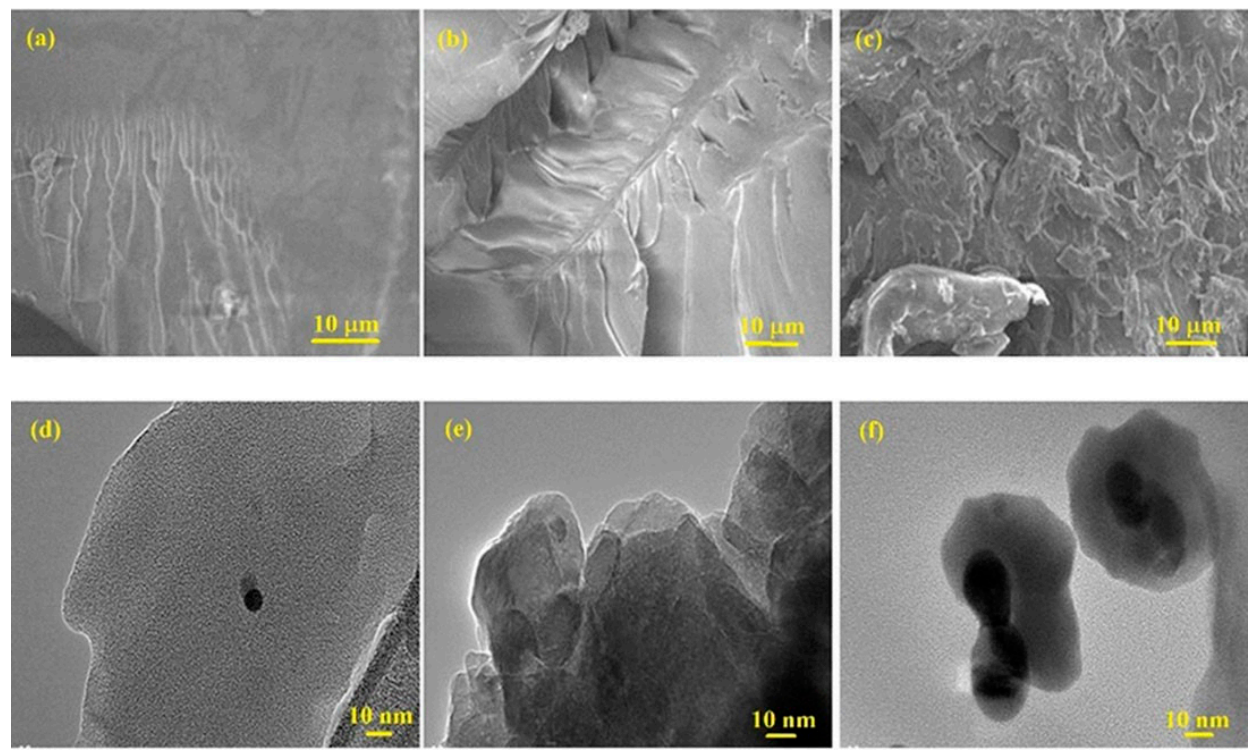

Figure 8. SEM and HRTEM micrographs of (a,d) PS-AgNPs; (b,e) PMMA-AgNPs; and (c,f) PS-PMMA-AgNPs nanocomposites (in situ).

TGA as used to investigate the thermal stability and interfacial interaction between the AgNPs and polymer matrices. Figure 9a present the TGA curves for the polymer/AgNPs composites using 
MWI and in situ reduction, respectively; with the inclusion of AgNPs, onset degradation temperature modification was observed. The temperature at which $5 \%$ of mass loss has occurred was used for measuring the degradation temperature. TGA results show that PS/AgNPs and PS-PMMA/AgNPs nanocomposites using in-situ method showed good thermal stability than that of MWI technique. Only in the case of PMMA/AgNPs composites, those prepared using MWI have slightly better thermal stability than those prepared in situ. We attributed this result to the presence and dispersion of AgNPs within the polymer matrix. In MWI, dielectric heating energy is transferred directly to the reactants, and the energy is supplied to the molecules faster than they are able to relax, creating high instantaneous temperatures that increase the yield and quality of the product, which is consistent with the results from our study. Among all the polymer/AgNPs nanocomposites, PS/AgNPs prepared by the in situ method showed the highest thermal stability. The values of degradation are summarized in Table 1. On the basis of these results, one disadvantage of MWI method is that the composites usually have lower thermal stability.

Table 1. Thermal behavior data of polymer/AgNP nanocomposites obtained from TGA and DSC measurements.

\begin{tabular}{cccc}
\hline Sample & $\boldsymbol{T}_{\operatorname{deg}}{ }^{a}\left(\mathbf{M W I},{ }^{\circ} \mathbf{C}\right)$ & $\boldsymbol{T}_{\text {deg }}{ }^{a}\left(\right.$ in situ,$\left.{ }^{\circ} \mathbf{C}\right)$ & $\boldsymbol{T}_{\mathbf{g}}{ }^{\mathbf{b}}\left(\mathbf{M W I},{ }^{\circ} \mathbf{C}\right)$ \\
\hline PS/AgNPs & 191 & 334 & 107 \\
PMMA/AgNPs & 232 & 202 & 130 \\
PS-PMMA/AgNPs & 159 & 198 & 110 \\
\hline \multicolumn{4}{c}{}
\end{tabular}

Figure $9 \mathrm{~b}$ shows the TGA plot of the neat polymers. The degradation of the neat polymers started at over 333, 176, and 300 for PS, PMMA, PSMMA, respectively (see Table S1). However, the PS/AgNPs (MWI) composite is less stable than pure PS; also, the composite PS-PMMA/AgNPs is less stable than pure PS-PMMA. Only in the case of PMMA/AgNPs (MWI) are the nanocomposites more stable than pure PMMA, and the thermal stability has been improved.

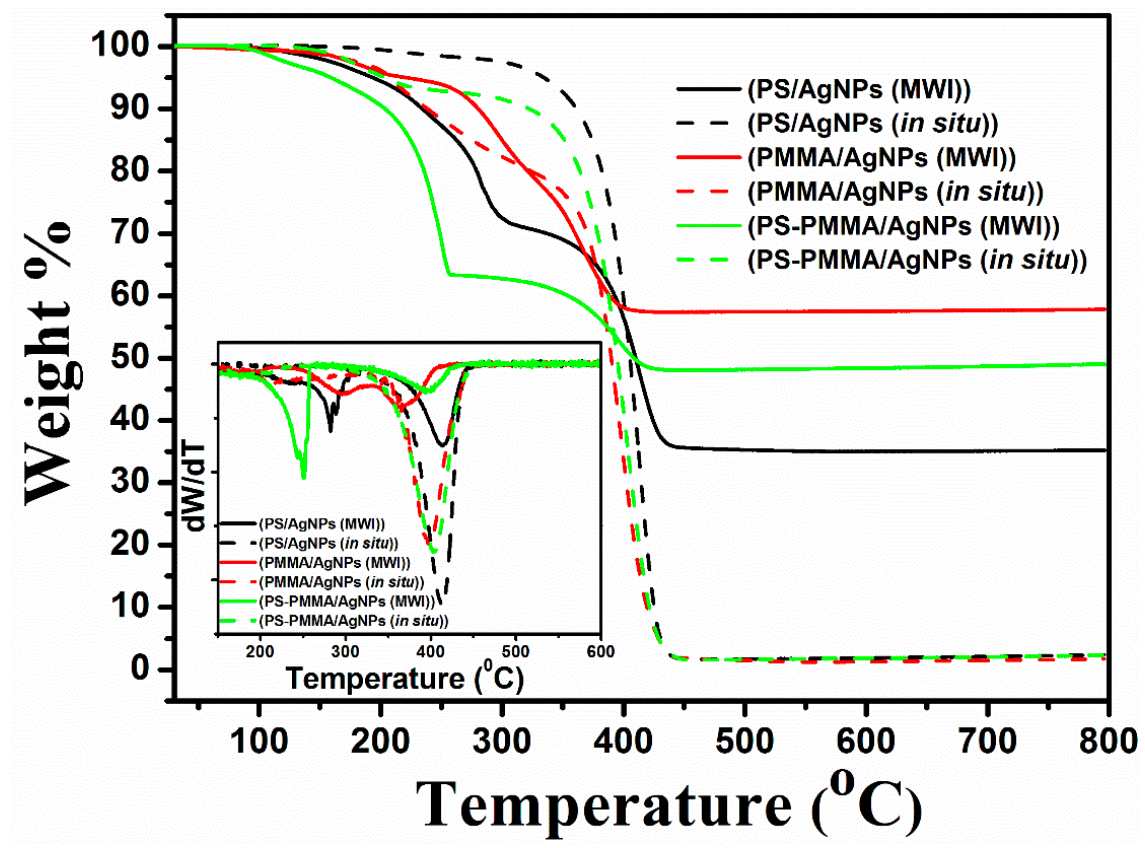

(a)

Figure 9. Cont. 


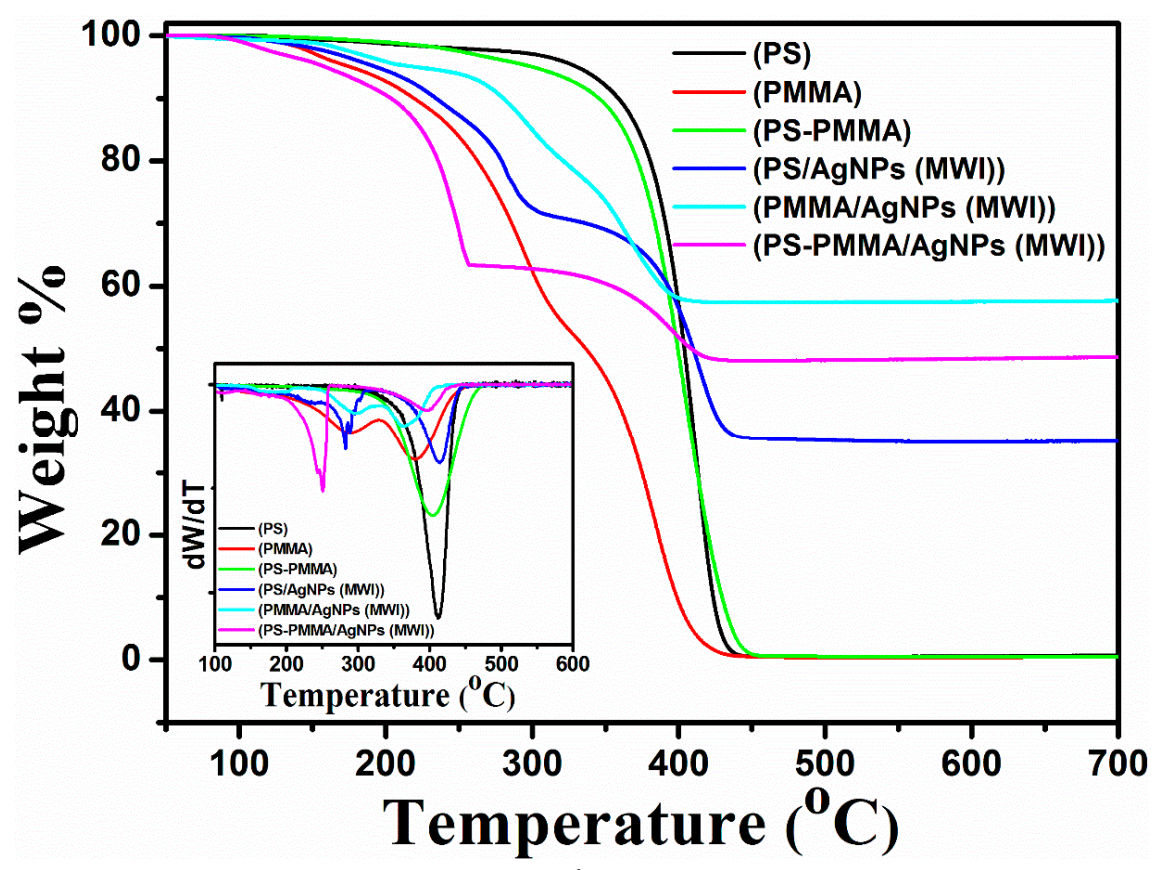

(b)

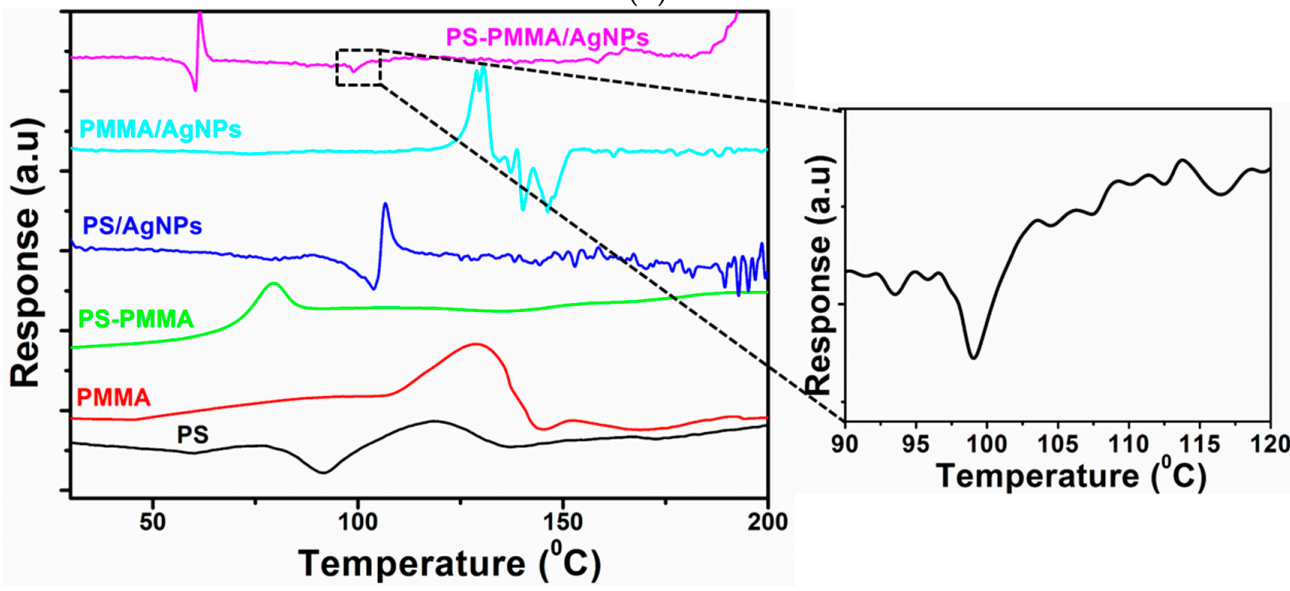

(c)

Figure 9. (a) TGA thermograms of polymer/AgNPs nanocomposites using MWI and in situ method; (b) TGA thermograms of neat polymers and polymer/AgNPs nanocomposites using MWI; (c) DSC thermograms of polymer/AgNPs nanocomposites and neat polymers. Bottom right: enlarged image of area marked by a box.

Therefore, our approach is promising for the development of a new class of polymer/metal NP composites. This result demonstrates that the thermal stability of the PMMA is improved because of the presence of AgNPs using the MWI method, which is consistent with the results obtained by [53].

To understand the effect of MWI on the thermal behavior and dispersion of AgNPs within the polymer matrix, DSC of the polymer/Ag composites was performed, and the results are presented in Figure 9c and summarized in Table 1. In order to get a clear picture of the degradation and the effect of AgNPs on the degradation temperature, DSC of the neat polymers was also performed and compared, as shown in Figure 9c. For the neat polymers, the Tg values are $118{ }^{\circ} \mathrm{C}, 127{ }^{\circ} \mathrm{C}$, and $79{ }^{\circ} \mathrm{C}$ for $\mathrm{PS}$, PMMA, and PS-PMMA, respectively (see Table S1). For the PS/Ag nanocomposites, the thermogram shows that the $T_{\mathrm{g}}$ value of the nanocomposites $\left(T_{\mathrm{g}}=107^{\circ} \mathrm{C}\right)$ decreased by $11^{\circ} \mathrm{C}$ compared with that of neat PS $\left(T_{\mathrm{g}}=118^{\circ} \mathrm{C}\right)$, as indicated in Table S1 also [54]. For the PMMA/AgNPs composite, the curve shows an improved thermal stability, with a $T_{\mathrm{g}}$ of $130{ }^{\circ} \mathrm{C}$, which is $3^{\circ} \mathrm{C}$ higher than that of the neat PMMA $\left(T_{\mathrm{g}}=127^{\circ} \mathrm{C}\right)$. For the PSMMA/AgNP composite, the curve shows a significantly improved 
thermal stability, with a $T_{\mathrm{g}}$ of $110^{\circ} \mathrm{C}$, which is $31^{\circ} \mathrm{C}$ higher than that of the neat PSMMA $\left(T_{\mathrm{g}}=79^{\circ} \mathrm{C}\right)$. This result suggests a very strong interaction between the PSMMA chains and AgNPs. Previous work has demonstrated that the interfacial strength between nanofillers and polymers and, consequently, the thermal properties of nanocomposites can be altered by varying the sample preparation method. In this work, the $T_{\mathrm{g}}$ shift may be attributed to the presence of so-called "interphase" polymer networking, which arises because of the interaction of the chains with the AgNPs surface, which may restrict the mobility, creating an enormous volume of matrix polymer. Percolation of this network of interphase polymer could then manifest as a large $T_{\mathrm{g}}$ shift of the polymer composite. Therefore, good dispersion without agglomeration of AgNPs may result from the fast thermal reduction process that is offered by MWI for PMMA/AgNPs and PSMMA/AgNPs nanocomposites, while the in situ method produced more stable nanocomposites.

Pure Ag is a good conductor; it is metallic, and its conductivity on the Pauling scale is $15.87 \mathrm{n} \Omega \cdot \mathrm{m}$ at $25^{\circ} \mathrm{C}$ [54] and in SI units is $\sim 6 \times 10^{5} \mathrm{~S} \mathrm{~cm}^{-1}$. As shown in Figure 10a, the Ps/Ag nanocomposites film exhibits a resistance of $\sim 1.45997 \Omega$ and a conductivity of $\sim 103 \mathrm{~S} / \mathrm{cm}$, which is significantly lower than that of pure $\mathrm{Ag}\left(\sim 6 \times 10^{5} \mathrm{~S} \mathrm{~cm}^{-1}\right)$. In addition, the Ps $\mathrm{Ag}$ nanocomposites film exhibits an Ohmic behavior, which is clearly observed in the plot. By comparing our results with the reported work on Ps / Ag nanowires (see Table 2), we observed that the conductivity values in our work are far superior to the reported ones. White et al. [55] reported that the conductivity of PS/Ag nanowire composites was $\sim 0.01 \mathrm{~S} / \mathrm{cm}$ for a nanowire aspect ratio of 8 , and the conductivity of Ps / Ag nanowire composites with an aspect ratio of 16 was $\sim 100 \mathrm{~S} / \mathrm{cm}$. Further increase of the aspect ratio of (31) resulted in a conductivity of $\sim 0.001 \mathrm{~S} / \mathrm{cm}$ for PS/Ag nanowire composites.
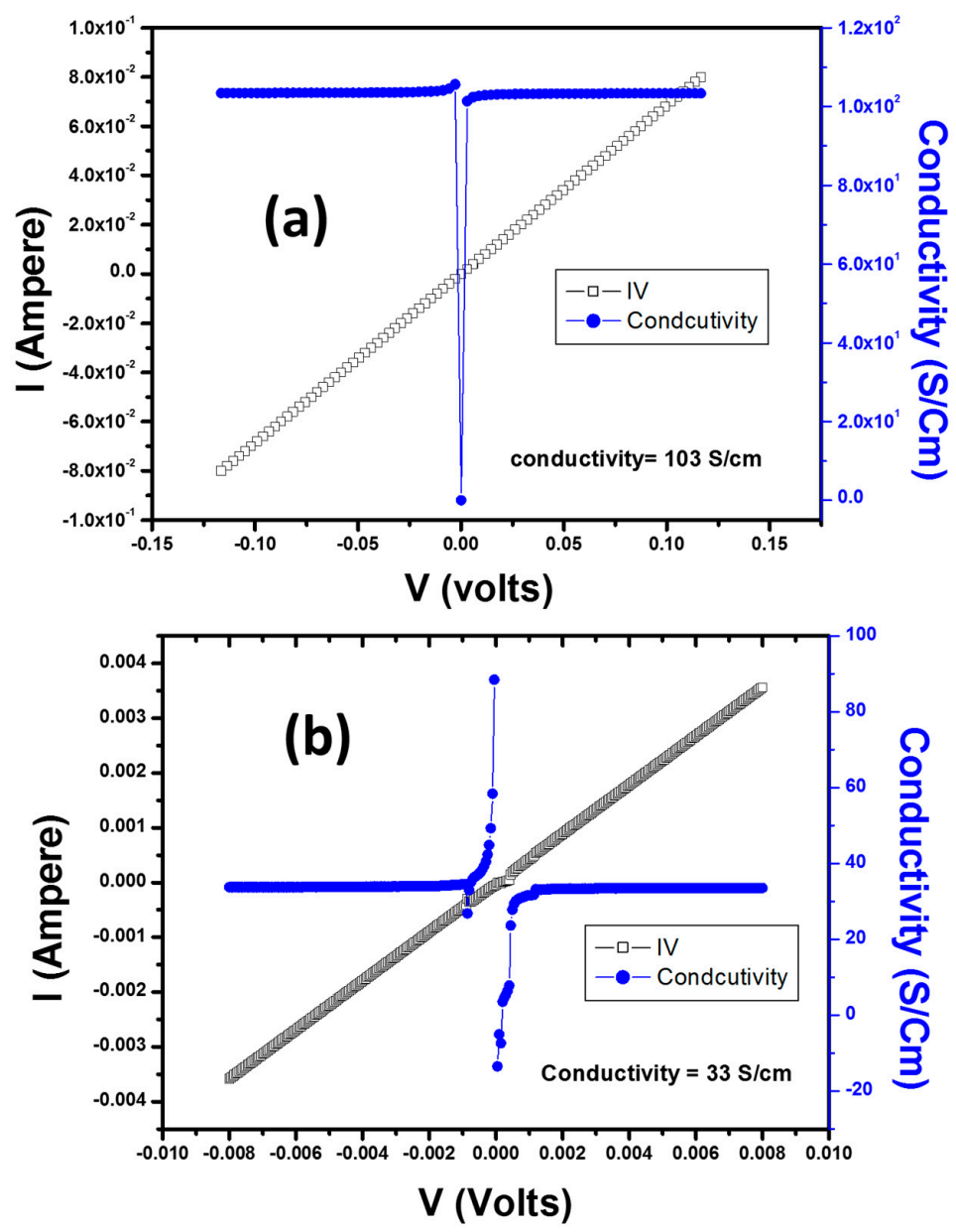

Figure 10. Cont. 


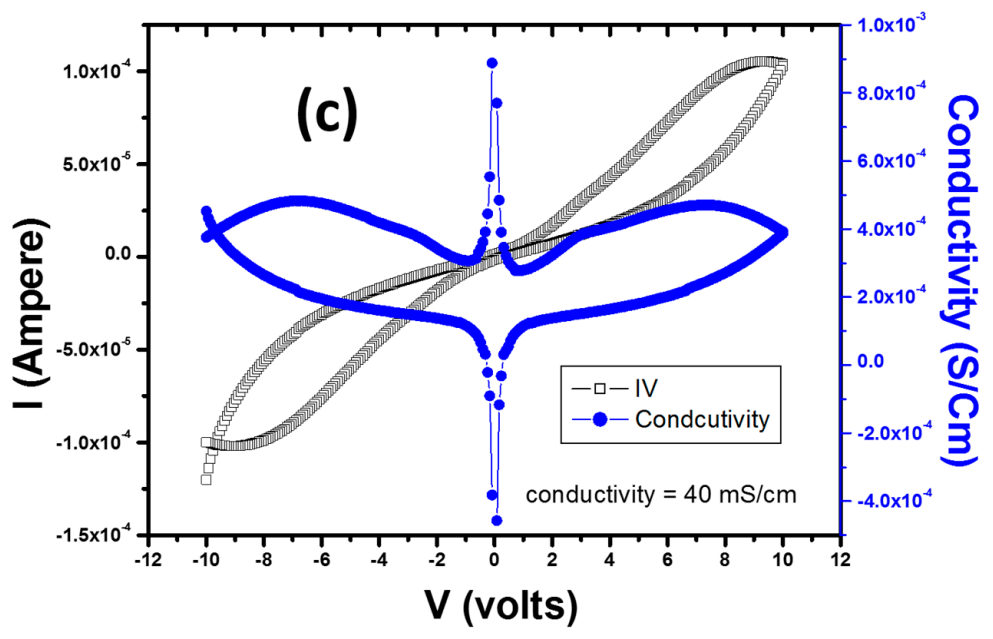

Figure 10. $I-V$ curves of (a) PS/AgNP; (b) PMMA/Ag; and (c) PSMMA/Ag nanocomposites.

When a polymer matrix is filled with a conducting filler, the composite gains a conductivity value of $\sigma$. When the loading of the filler is increased such that the volume filler fraction $\varphi$ reaches a critical value $\varphi_{\mathrm{c}}$, an infinite cluster is formed, and the composite becomes conducting [54]. Because of the presence of a conduction or percolation path across the entire sample, a change from an insulator to a semiconductor occurs. As the filler concentration increases to the filling limit $F$, the value of $r$ increases rapidly over several orders of magnitude from the value $r_{c}$ at the percolation threshold to the maximal value $\sigma_{\mathrm{m}}$. Above the percolation threshold, the electrical conductivity is related to the content of conducting filler. To produce a conducting AgNPs/PMMA nanocomposites, $\sim 16 \mathrm{wt} \%$ loading of AgNPs would be needed, as per the requirement of the percolation threshold. Therefore, in our case for PMMA/Ag nanocomposites, as illustrated in Figure 10b, we used $20 \mathrm{wt} \%$ of AgNPs, which produced conducting composites. For the percolation to occur, the volume occupied by the conducting phase in the composite is most important, which explains why the PMMA/Ag nanocomposites produced were conducting because of the percolation threshold.

Table 2. Resistance and conductivity of polymer/AgNP nanocomposites.

\begin{tabular}{cccc}
\hline Nanocomposites & Resistance $\mathbf{( O h m )}$ & Conductivity $\mathbf{( S / c m )}$ & References \\
\hline Ag & $10-5^{-5}$ & $6 \times 10^{5}$ & {$[52]$} \\
PS & $10^{2}-10^{7}$ & $10-2$ to $10-7$ & {$[53]$} \\
PMMA & $10^{14}-10^{16}$ & $10^{-14}$ to $10^{-16}$ & {$[53]$} \\
PS/Ag nanowires (A.R = 8) & $10^{2}$ & $1 \times 10^{-2}$ & {$[53]$} \\
PS/Ag nanowires (A.R =31) & $10^{3}$ & $1 \times 10^{-3}$ & {$[53]$} \\
PS/Ag & $10^{-1}$ & $1.4 \times 10^{-1}$ & {$[54]$} \\
PMMA/Ag & $10^{14}-10^{7}$ & $10^{-14}-10^{-7}$ & {$[55]$} \\
PANI-PMMA/Ag & $10^{9}-10^{-4}$ & $10^{-9}-10^{4}$ & Our Work \\
PS/Ag & 1.46 & $1.03 \times 10^{2}$ & Our Work \\
PMMA/Ag & $10^{-1}$ & $3.3 \times 10$ & Our Work \\
PS-PMMA/Ag & $73.98 \times 10^{3}$ & $40 \times 10^{-3}$ & \\
\hline
\end{tabular}

For the PSMMA / Ag nanocomposites, we obtained a resistance of $\sim 73.98347 \mathrm{k} \Omega$ and a conductivity of $\sim 40 \mathrm{mS} / \mathrm{cm}$ with non-ohmic behavior, as shown in Figure 10c. These resistance and conductivity values indicate that the electrical properties of the nanocomposites were enhanced compared with that of pure PS and PMMA (see Table 1). The resistance values for pure PS and PMMA are $10^{2}-10^{7} \Omega$ and $10^{14}-10^{16} \Omega$, respectively. To the best of our knowledge, this paper is the first to report the electrical properties of PSMMA/Ag nanocomposites. Lee et al. [31] reported on the effect of polyaniline on the conductivity of a PMMA/Ag hybrid composite. These researchers demonstrated that the resistivity of 
PMMA/Ag varied from $10^{14}$ to $10^{7} \Omega$-cm, whereas that of PMMA/PANI/Ag composites varied from $10^{9}$ to $10^{-4} \Omega-\mathrm{cm}$. Thus, the resistivity of the PMMA/PANI/Ag composites was much lower than that of the PMMA/Ag composites, indicating that PANI strongly enhanced the conductivity. However, in our case, the resistivity is much lower than that of this work, resulting in the higher conductivity value.

\section{Materials and Methods}

\subsection{Materials}

Styrene (S) and methyl methacrylate (MMA) monomers (99\%, Acros Chemical Co., One Reagent Lane, Fair Lawn, NJ, USA) were stored in a refrigerator and used as received. Benzoyl peroxide (BP) (BDH Chemicals Ltd., Dammam, Saudi Arabia) was used as an initiator, hydrazine hydrate $(\mathrm{HH}, 80 \%)$ was obtained from LobaChemi. Pvt. Ltd., Mumbai, India and silver nitrate $\left(\mathrm{AgNO}_{3}\right)$ was obtained from Merck., Kenilworth, NJ, USA. The other solvents and chemicals were of analytical grade and used without further purification.

\subsection{MWI Preparation of PS/Ag, PMMA/Ag, and PS-PMMA/Ag Nanocomposites}

A mixture of $2.0 \mathrm{~g}$ (S-MMA) monomers, $80 \mathrm{mg} \mathrm{AgNO}_{3}$, and $0.1 \mathrm{~g}$ BP was sonicated for $1 \mathrm{~h}$, and then, the mixture were maintained at $60^{\circ} \mathrm{C}$ for $20 \mathrm{~h}$ to promote in situ free radical bulk polymerization. After the polymerization was completed, the product was poured into an excess of methanol, stirred for $15 \mathrm{~min}$, and washed with methanol and hot water several times before being filtered and dried in an oven at $80^{\circ} \mathrm{C}$ overnight. Then, a mixture of $0.40 \mathrm{~g}$ (PS-PMMA) polymer $/ \mathrm{AgNO}_{3}$ composites dissolved into a solvent, $40 \mu \mathrm{L}$ of $\mathrm{HH}$, was sonicated for $1 \mathrm{~h}$ followed by reduction using MWI. The same procedure was performed with PS and PMMA.

\subsection{In Situ Preparation of PS/Ag, PMMA/Ag, and PS-PMMA/Ag Nanocomposites}

A mixture of $2.0 \mathrm{~g}$ (S-MMA) monomers, $80 \mathrm{mg}$ AgNPs (prepared via MWI reduction of $\mathrm{AgNO}_{3}$ ), and $0.1 \mathrm{~g}$ BP was sonicated for $1 \mathrm{~h}$, and then the mixture was maintained at $60^{\circ} \mathrm{C}$ for $20 \mathrm{~h}$ to promote in situ free radical bulk polymerization. After the polymerization was completed, the product was poured into an excess of methanol, stirred for $15 \mathrm{~min}$, and washed with methanol and hot water several times before being filtered and dried in an oven at $80^{\circ} \mathrm{C}$ overnight. The same procedure was performed with PS and PMMA. The neat PS, PMMA, and PS-PMMA were prepared for comparison using the same procedure but without the addition of AgNPs.

\subsection{Characterization}

The FTIR spectra (Thermo Scientific, Waltham, MA, USA, Nicolet-iS10) of the nanocomposites were recorded in the range of $4000-500 \mathrm{~cm}^{-1}$. The UV-Vis spectra (Perkin-Elmer Lambda 35, Waltham, MA, USA) of the nanocomposites were recorded in the range of 200-800 nm. XRD analysis (Philips-Holland, Amsterdam, The Netherlands, PW 1729) of the nanocomposites was performed using $\mathrm{Cu}$ radiation $\left(30 \mathrm{kV}, 40 \mathrm{~mA}, \mathrm{~K} \alpha\right.$ radiation $(\lambda=1.54430 \AA)$ ) between $2 \theta$ of $5^{\circ}$ and $100^{\circ}$. The XPS measurements were performed using a SPECS GmbH X-ray photoelectron spectrometer. Before analysis, the samples were degassed under a vacuum inside the load lock for $16 \mathrm{~h}$. The Raman spectra of nanocomposites were measured using a Bruker Equinox 55 FT-IR spectrometer equipped with an FRA106/S FT-Raman module and a liquid $\mathrm{N}_{2}$-cooled Ge detector using the $1064 \mathrm{~nm}$ line of a Nd:yttrium aluminum garnet laser with an output laser power of $200 \mathrm{~mW}$. SEM (FEI Quanta 200, FEI, Hillsboro, OR, USA) was employed to examine the morphology of the nanocomposites after they were mounted on the nanocomposite slabs and coated with Au via a sputtering system (Polaron E6100, Bio-Rad, Herts HP2 7DX, Hemel Hempstead, UK). HRTEM (JEOL JSM-2100F, Tokyo, Japan) was performed at $200 \mathrm{kV}$. A drop of the composite dispersed in ethanol was placed on copper grids and dried for studies. TGA of the nanocomposites was performed under an $\mathrm{N}_{2}$ atmosphere at a heating rate of $10{ }^{\circ} \mathrm{C}$ per minute from $25^{\circ} \mathrm{C}$ to $800{ }^{\circ} \mathrm{C}$ using a NETZCH $209 \mathrm{~F} 1$ thermogravimetric analyzer. 
DSC (NETZCH 204 F1) measurements were employed to estimate the glass-transition temperature $\left(T_{\mathrm{g}}\right)$ of each nanocomposite. The nanocomposites were heated from $-25^{\circ} \mathrm{C}$ to $100{ }^{\circ} \mathrm{C}$ at a heating rate of $10{ }^{\circ} \mathrm{C}$ per min. Then, a double run was performed after cooling at a heating rate of $2{ }^{\circ} \mathrm{C}$ per min from $25{ }^{\circ} \mathrm{C}$ to $350{ }^{\circ} \mathrm{C}$. The $T_{\mathrm{g}}$ was taken as the midpoint of the transition. The resistances of the nanocomposites were calculated using two point probe method in a two-electrode $(\mathrm{Cu})$ configuration by using a Keithley 4200 SCS-four-probe electrical current-voltage $(I-V)$ measurements system. The conductivities of the samples were calculated by fitting their $I-V$ characteristics (10 cycles). After the measurements were taken, the mass of the film consisting of each composite was measured (for PS $/ \mathrm{AgNPs}=1 \mathrm{mg}$, PMMA/AgNPs $=2 \mathrm{mg}$, PS-PMMA/AgNPs $=4 \mathrm{mg}$ ), and the effective thickness of each film was calculated (for PS/AgNPs $=0.1 \mathrm{~mm}$, PMMA $/ \mathrm{AgNPs}=0.2 \mathrm{~mm}$, PS-PMMA $/ \mathrm{AgNPs}=0.4 \mathrm{~mm}$ )). This procedure yielded a value of the film conductivity from the measured resistance.

\section{Conclusions}

In conclusion, the incorporation of AgNPs within PS, PMMA, and PSMMA co-polymer matrices using in situ bulk polymerization and MWI was achieved, and the resulting functional properties were compared. FTIR and XPS studies confirmed the formation of metallic AgNPs within the polymer matrix. UV-Vis spectra of the PS/Ag and PMMA/Ag nanocomposites revealed a red shift with respect to the PSMMA/Ag nanocomposites, confirming the size effect of AgNPs. Raman spectra indicated that the characteristics peaks of all the polymer/Ag nanocomposites were blue-shifted with respect to the neat polymer, which indicates interfacial interactions between the AgNPs and polymer matrix. SEM and HRTEM micrographs of the polymer/AgNPs revealed that the AgNPs dispersed at the surface and embedded within the polymer matrix. TGA and DSC results revealed a modification in the thermal stability using AgNPs within the polymer matrix. These results indicate that the nanocomposites obtained using in situ technique exhibited better thermal stability than MWI-except PMMA/AgNPs (MWI), which showed better thermal stability than the in situ method. The electrical conductivity of the nanocomposites significantly improved, and the PS/Ag nanocomposites exhibited the highest conductivity, which is governed by the percolation model. These nanocomposites may prove particularly effective for the design of fuel cell electrodes, which are often made with conductive nanocomposites, or simply mats of conductive particles.

Supplementary Materials: The following are available online at www.mdpi.com/1996-1944/9/6/458/s1. Figure S1: FTIR Spectra of Neat Polymers Polystyrene (PS), Poly methyl methacrylate (PMMA), and Polystyrene-Poly(methyl methacrylate) (PS/PMMA); Figure S2: Raman spectra of polymers Polystyrene (PS), Poly methyl methacrylate (PMMA), and Polystyrene-Poly(methyl methacrylate) (PS/PMMA); Table S1: Summary of the thermal behavior data obtained from TGA and DSC measurements.

Acknowledgments: This study is a part of the research Project No. 405010901101. The author gratefully acknowledges the continued support of Alfaisal University and its Office of Research.

Conflicts of Interest: The author declares no conflict of interest.

\section{References}

1. Kampf, G.; Dietze, B.; Große-Siestrup, C.; Wendt, C.; Martiny, H. Microbicidal activity of a new silver-containing polymer, SPI-ARGENT II. Antimicrob. Agents Chemother. 1998, 42, 2440-2442. [PubMed]

2. Fang, N.; Lee, H.; Sun, C.; Zhang, X. Sub-diffraction-limited optical imaging with a silver superlens. Science 2005, 308, 534-537. [CrossRef] [PubMed]

3. Sun, Y.; Gates, B.; Mayers, B.; Xia, Y. Crystalline silver nanowires by soft solution processing. Nano Lett. 2002, 2, 165-168. [CrossRef]

4. $\quad$ Nicewarner-Pena, S.R.; Freemean, R.G.; Reiss, B.D.; He, L.; Pena, D.J.; Walton, I.D.; Cromer, R.; Keating, C.D.; Natan, M.J. Submicrometer metallic barcodes. Science 2001, 294, 137-141. [CrossRef] [PubMed]

5. Mock, J.J.; Oldenburg, S.J.; Smith, D.R.; Schultz, D.A.; Schultz, S. Composite plasmon resonant nanowires. Nano Lett. 2002, 5, 465-469. [CrossRef] 
6. Mailard, M.; Huang, O.; Brus, L. Silver Nanodisk growth by surface plasmon enhanced photoreduction of adsorbed $\left[\mathrm{Ag}^{+}\right.$]. Nano Lett. 2003, 3, 1611-1615. [CrossRef]

7. Haes, A.J.; Stuart, D.A.; Nie, S.; van Dyyene, R.P. Using solution-phase nanoparticles, surface-confined nanoparticle arrays and single nanoparticles as biological sensing platforms. J. Fluoresc. 2004, 14, 355-367. [CrossRef] [PubMed]

8. Mock, J.J.; Barbic, M.; Smith, D.R.; Schultz, D.A.; Schultz, S. Shape effects in plasmon resonance of individual colloidal silver nanoparticles. J. Chem. Phys. 2002, 116, 6755-6759. [CrossRef]

9. Yeo, S.Y.; Jeong, S.H. Preparation and characterization of polypropylene/silver nanocomposite fibers. Polym. Int. 2003, 52, 1053-1057. [CrossRef]

10. Feng, Q.L.; Wu, J.; Chen, G.Q.; Cui, F.Z.; Kim, T.N.; Kim, J.O. A mechanistic study of the antibacterial effect of silver ions on Escherichia coli and Staphylococcus aureus. J. Biomed. Mater. Res. A 2000, 52, 662-668. [CrossRef]

11. Gupta, A.; Silver, S.S. Molecular genetics: Silver as a biocide: Will resistance become a problem? Nat. Biotechnol. 1998, 16, 888. [CrossRef] [PubMed]

12. Pumera, M. Graphene in biosensing. Mater. Today 2011, 14, 308-315. [CrossRef]

13. Gubin, S.P. Metalcontaining nano-particles within polymeric matrices: Preparation, structure, and properties. Colloids Surf. A 2002, 202, 155-163. [CrossRef]

14. Hong, W.; Woo, H.-J.; Choi, H.-W.; Kim, Y.-S.; Kim, G.-D. Optical property modification of PMMA by ion-beam implantation. Appl. Surf. Sci. 2001, 169-170, 428-432. [CrossRef]

15. Johnson, P.B.; Christy, R.W. Optical constants of the noble metals. Phys. Rev. B 1972, 16, 4370-4379. [CrossRef]

16. Abdelsayed, V.; Alsharaeh, E.; El-Shall, M.S. Catalyzed radical polymerization of styrene vapor on nanoparticle surfaces and the incorporation of metal and metal oxide nanoparticles within polystyrene polymers. J. Phys. Chem. B 2006, 110, 19100-19103. [CrossRef] [PubMed]

17. Alsharaeh, E.H.; Othman, A.A. Microwave irradiation synthesis and characterization of RGO-AgNPs/polystyrene nanocomposites. Polym. Compos. 2014, 35, 2318-2323. [CrossRef]

18. Alsharaeh, E.H.; Othman, A.A.; Aldosari, M.A. Microwave irradiation effect on the dispersion and thermal stability of rgo nanosheets within a polystyrene matrix. Materials 2014, 7, 5212-5224. [CrossRef]

19. Matusinovic, Z.; Rogosic, M.; Sipusic, J. Synthesis and characterization of poly(styrene-co-methyl methacrylate)/layered double hydroxide nanocomposites via in situ polymerization. Polym. Degrad. Stab. 2009, 94, 95-101. [CrossRef]

20. Coskun, M.; Seven, P. Synthesis, characterization and investigation of dielectric properties of two-armed graft copolymers prepared with methyl methacrylate and styrene onto PVC using atom transfer radical polymerization. React. Funct. Polym. 2011, 71, 395-401. [CrossRef]

21. Wei, H.; Eilers, H. Electrical conductivity of thin-film composites containing silver nanoparticles embedded in a dielectric fluoropolymer matrix. Thin Solid Films 2008, 517, 575-581. [CrossRef]

22. Du, B.D.; Phu, D.V.; Duy, N.N.; Lan, N.T.K.; Lang, V.T.K.; KeThanh, N.V.; Phong, N.T.P.; QuocHien, N. Preparation of colloidal silver nanoparticles in poly( $\mathrm{N}$-vinylpyrrolidone) by $\gamma$-irradiation. J. Exp. Nanosci. 2008, 3, 207-213. [CrossRef]

23. Huang, X.; Yin, Z.Y.; Wu, S.X.; Qi, X.Y.; He, Q.Y.; Zhang, Q.C.; Yan, Q.Y.; Boey, F.; Zhang, H. Graphene-Based Materials: Synthesis, Characterization, Properties, and Applications. Small 2011, 7, 1876-1902. [CrossRef] [PubMed]

24. Aldosari, M.; Othman, A.; Alsharaeh, E. Synthesis and Characterization of the in Situ Bulk Polymerization of PMMA Containing Graphene Sheets Using Microwave Irradiation. Molecules 2013, 18, 3152-3167. [CrossRef] [PubMed]

25. Hassan, H.M.A.; Abdelsayed, V.; Khder, A.; AbouZeid, K.M.; Terner, J.; El-Shall, M.S.; Al-Resayes, S.I.; El-Azhary, A.A. Microwave synthesis of graphene sheets supporting metal nanocrystals in aqueous and organic media. J. Mater. Chem. 2009, 19, 3832-3837. [CrossRef]

26. Zedan, A.F.; Sappal, S.; Moussa, S.; El-Shall, M.S. Ligand-controlled microwave synthesis of cubic and hexagonal CdSe nanocrystals supported on graphene. Photoluminescence quenching by graphene. J. Phys. Chem. C 2010, 114, 19920-19927. [CrossRef]

27. Siamaki, A.R.; Khder, A.E.R.S.; Abdelsayed, V.; El-Shall, M.S.; Gupton, B.F. Microwave-assisted synthesis of palladium nanoparticles supported on graphene: A highly active and recyclable catalyst for carbon-carbon cross-coupling reactions. J. Catal. 2011, 279, 1-11. [CrossRef] 
28. Herring, N.; Almahoudi, S.; Olson, C.; El-Shall, M.S. Enhanced photocatalytic activity of ZnO-graphene nanocomposites prepared by microwave synthesis. J. Nanopart. Res. 2012, 14, 1-13. [CrossRef]

29. Chung, D.D.L. Electrical applications of carbon materials. J. Mater. Sci. 2004, 39, 2645-2661. [CrossRef]

30. Vodnik, V.; Božanić, D.K.; Džunuzović, J.V.; Vukoje, I.; Nedeljković, J. Silver/polystyrene nanocomposites: Optical and thermal properties. Polym. Compos. 2012, 33, 782-788. [CrossRef]

31. Lee, Y.; Kim, E.; Kim, K.; Lee, B.H.; Choe, S. Polyaniline effect on the conductivity of the PMMA/Ag hybrid composite. Colloids Surf. A 2012, 396, 195-202. [CrossRef]

32. White, S.I.; Mutiso, R.M.; Vora, P.M.; Jahnke, D.; Hsu, S.; Kikkawa, J.M.; Li, J.; Fischer, J.E.; Winey, K.I. Electrical percolation behavior in silver nanowire-polystyrene composites: Simulation and experiment. Adv. Funct. Mater. 2010, 20, 2709-2716. [CrossRef]

33. Warren, B.E. X-ray Diffraction; Addison Wesley Publishing Co.: London, UK, 1969.

34. NIST-XPS Database. Available online: http://srdata.nist.gov/xps/2000 (accessed on 8 December 2009).

35. Gröning, P.; Collaud, M.; Dietler, G.; Schlapbach, L. Plasma modification of polymethylmethacrylate and polyethyleneterephthalate surfaces. J. Appl. Phys. 1994, 76, 887-892. [CrossRef]

36. Burkstrand, J.M. "Hot" atom interactions with polymer surfaces. J. Vac. Sci. Technol. 1982, 21, 70-73. [CrossRef]

37. Burkstrand, J.M. Metal-polymer interfaces: Adhesion and X-ray photoemission studies. J. Appl. Phys. 1981, 52, 4795-4800. [CrossRef]

38. Henneuse-Boxus, C.; Poleunis, C.; Ro, A.D.; Adriaensen, Y.; Bertrand, P.; Marchand-Brynaert, J. Surface functionalization of PEEK films studied by time-of-flight secondary ion mass spectrometry and X-ray photoelectron spectroscopy. Surf. Interface Anal. 1999, 27, 142-152. [CrossRef]

39. Yang, Y.; Liu, S.; Kimura, K. Superlattice formation from polydisperse Ag nanoparticles by a VAPor-diffusion method. Angew. Chem. Int. Ed. 2006, 45, 5662-5665. [CrossRef] [PubMed]

40. Gupta, N.R.; Prasad, B.L.V.; Gopinath, C.S.; Badiger, M.V. A nanocomposite of silver and thermo-associating polymer by a green route: A potential soft-hard material for controlled drug release. RSC Adv. 2014, 4, 10261-10268. [CrossRef]

41. Mulvaney, P. Surface plasmon spectroscopy of nanosized metal particles. Langmuir 1996, 12, 788-800. [CrossRef]

42. Carotenuto, G.; Palomba, M.; Nicolais, L. Nanocomposite synthesis by thermolysis of $[\mathrm{Ag}(\mathrm{hfac})(\mathrm{COD})]$ in amorphous polystyrene. Sci. Eng. Compos. Mater. 2012, 19, 195-197. [CrossRef]

43. Singho, N.; Johan, M.; Lah, N.A. Temperature-dependent properties of silver-poly(methylmethacrylate) nanocomposites synthesized by in-situ technique. Nanoscale Res. Lett. 2014, 9, 42. [CrossRef] [PubMed]

44. Nobel, M.L.; Mendes, E.; Picken, S.J. Acrylic-based nanocomposite resins for coating applications. J. Appl. Polym. Sci. 2007, 104, 2146-2156. [CrossRef]

45. Van Hamersveld, E.M.S.; van Es, J.J.G.S.; German, A.L.; Cuperus, F.P.; Weissenborn, P.; Hellgren, A.C. Oil-acrylic hybrid latexes as binders for waterborne coatings. Prog. Org. Coat. 1999, 35, 235-246. [CrossRef]

46. Tigli, R.S.; Evren, V. Synthesis and characterization of pure poly(acrylate) latexes. Prog. Org. Coat. 2005, 52, 144-150. [CrossRef]

47. Chen, B.; Evans, J.R.G.; Greenwell, C.H.; Boulet, P.; Coveney, P.V.; Bowden, A.A.; Whiting, A.A. A critical appraisal of polymer-clay nanocomposites. Chem. Soc. Rev. 2008, 37, 568-594. [CrossRef] [PubMed]

48. Chow, W.S.; Ishak, Z.A.M. Effects of compatibilizers and testing speeds on the mechanical properties of organophilic montmorillonite filled polyamide 6/polypropylene nanocomposites. Polym. Lett. 2007, 1, 77-83. [CrossRef]

49. Marrink, S.J.; Risselada, H.J.; Yefimov, S.; Tieleman, P.D.; Vries, A. The MARTINI Force Field: Coarse Grained Model for Biomolecular Simulations. J. Phys. Chem. B 2007, 111, 7812-7824. [CrossRef] [PubMed]

50. Manoudis, P.; Papadopoulou, S.; Karapanagiotis, I.; Tsakalof, A.; Zuburtikudis, I.; Panayiotou, C. Polymer-Silica nanoparticles composite films as protective coatings for stone-based monuments. J. Phys. Conf. Ser. 2007, 61, 1361-1365. [CrossRef]

51. Desai, T.; Keblinski, P.; Kumar, S.K. Molecular dynamics simulations of polymer transport in nanocomposites. J. Chem. Phys. 2005, 122, 134910. [CrossRef] [PubMed]

52. Gilman, J.W.; Jackson, C.L.; Morgan, A.B.; Harris, R., Jr.; Manias, E.; Giannelis, E.P.; Wuthenow, M.; Hilton, D.; Phillips, S.H. Flammability properties of polymer-layered-silicate nanocomposites. Polypropylene and polystyrene nanocomposites. Chem. Mater. 2000, 12, 1866-1873. [CrossRef] 
53. Mbhele, Z.H.; Salemane, M.G.; vanSittert, C.G.C.E.; Nedeljković, J.M.; Djoković, V.; Luyt, A.S. Fabrication and characterization of silver-polyvinyl alcohol nanocomposites. J. Chem. Mater. 2003, 15, 5019-5024. [CrossRef]

54. Periodic Table of Elements and Chemistry. Available online: http://www.chemicool.com/elements/silver. html (accessed on 1 March 2011).

55. Stauffer, D. Introduction to Percolation Theory; Taylor and Francis: London, UK, 1985.

(C) 2016 by the author; licensee MDPI, Basel, Switzerland. This article is an open access article distributed under the terms and conditions of the Creative Commons Attribution (CC-BY) license (http://creativecommons.org/licenses/by/4.0/). 